\title{
A New Methodology for Measurement of Semi-Solid Constitutive Behavior and its Application to Examination of As-Cast Porosity and Hot Tearing in Aluminum Alloys
}

\author{
A.B. Phillion ${ }^{1}$, S.L. Cockcroft ${ }^{1}$, and P.D. Lee $^{2}$ \\ ${ }^{1}$ Department of Materials Engineering, University of British Columbia, Vancouver CA \\ ${ }^{2}$ Department of Materials, Imperial College London, London, UK \\ Keywords: Semi-solid tensile deformation; X-ray tomography; Hot tearing; Porosity
}

\begin{abstract}
Hot tearing and as-cast porosity are two defects which impede the performance of cast products. The effect of porosity on hot tearing was investigated using a novel semi-solid tensile deformation methodology combined with $x$-ray micro-tomography. Semi-solid deformation tests were conducted on the commercial aluminum-magnesium alloy AA5182 in the as-cast state. This material was tested in two forms: as-received and hot isostatically pressed. In all cases, processing via hot isostatic pressing was found to increase the semisolid tensile strength and ductility by reducing the number of pre-existing nucleation sites for strain accommodation. Further, it was shown that failure in this material is localized to the fracture surface with very little internal damage occurring in other areas. These results support the hypothesis that as-cast porosity is intimately linked to the hot tearing susceptibility of aluminum alloys.
\end{abstract}

\section{Introduction and Background}

During casting of aluminum alloys, the semi-solid material is frequently exposed to a tensile stress state due to temperature gradients and mechanical constraints. The response of the semi-solid phase to these tensile stresses is critical in controlling many solidification defects such as hot tearing [1-7] and porosity [8-13]. These defects in turn affect productivity and the mechanical properties of the cast material [7, 14].

Both hot tearing and porosity are related to semi-solid constitutive behavior. Hot tearing is a stress-related defect $[15,16]$, while porosity is related to stress via the coefficient of thermal expansion and solidification shrinkage. Although a few authors have shown experimentally that hot tears nucleate at specific intergranular voids $($ e.g. $[5,17])$, the role of as-cast porosity on hot tearing has not yet been fully explored. One study which examined both hot tearing and porosity was performed by Suyitno et al. [18], who developed a model to differentiate between void formation leading to microporosity and void formation leading to hot tearing. While this model presented a sophisticated approach to hot tearing prediction, it assumed no 
interaction between hot tearing and porosity, nor was any experimental evidence presented. To better elucidate the role of as-cast porosity on hot tearing, it is proposed to investigate the effect of porosity on semi-solid constitutive behavior.

In order to undertake this study, a robust apparatus for conducting the semi-solid deformation tests is required. Many different techniques have been previously developed to the measure the shear [19-21], compressive [22-24], and tensile [25-36] behavior of semisolid materials. Of these tests, the tensile behavior is the most relevant since excessive accumulation of tensile strain can lead to openings in the semi-solid microstructure and thus a hot tear. These tensile tests have shown that semi-solid strength is strongly dependent on the fraction solid, microstructure size, morphology, and especially alloy chemistry [28, 36, 37]. Furthermore, these tests point to the presence of two characteristic transitions in terms of constitutive behavior. The first transition is the mechanical coherency point, which lies in the range of fraction solid between $\sim 0.90-0.95[25,32]$, and characterizes the ability of a semisolid material to sustain tensile stress. The second transition is the mechanical ductility point, which is reported to develop only at fraction solids close to unity [28, 33], and characterizes the ability of a semi-solid material to accommodate tensile strain.

Previous researchers have adopted two basic techniques for investigating semi-solid tensile constitutive behavior: partial remelting of the solid sample (e.g. [25]), and in situ solidification of the liquid melt (e.g. [33]). Of the two approaches, the solidification tests are a better approximation to the conditions prevailing during casting processes, since it is possible for mass feeding of the liquid metal to occur. However, it is difficult in these tests to extract quantitative stress and strain data. Quantitative data is much more straightforward in the partial remelting test apparatus, since a conventional tensile tester may be used.

In the partial remelting test, which is the subject of this paper, there are three inherent challenges with respect to measurement of semi-solid constitutive behavior. Firstly, thermal control is critical as small changes in temperature and fraction solid can greatly affect the constitutive behavior. Secondly, measurement of the semi-solid ductility is complex and deformation localizes even at small values of strain. Thirdly, fixed grips cannot be used since they would apply a compressive load during heating, due to thermal expansion, and lead to the accumulation of inelastic strain. Failure to address one or more of these challenges can result in problems with reproducibility. For example, the semi-solid flow stress measured by Colley [25] for AA5182 was $9 \mathrm{MPa}$ at $560^{\circ} \mathrm{C}$ at a strain rate of $10^{-4}$, while the value measured by Van Haaften [31] was $3 \mathrm{MPa}$ at a similar strain rate. Kron [28] and Twite's [30] results for AA6061 also differ by similar amounts. 
In this paper, a new methodology for conducting semi-solid tensile tests using the partial remelting approach is presented. This methodology reduces the effects of the three testing challenges highlighted above using novel techniques for temperature and displacement control within a Gleeble $3500^{1}$ thermomechanical simulator. The methodology is then applied to investigate the constitutive behavior of a semi-solid commercial $\mathrm{Al}-\mathrm{Mg}$ alloy in the as-cast and as-cast plus hot isostatic pressing states (the latter containing little or no porosity), elucidating the role of as-cast porosity on hot tearing.

\section{Experimental Methodology}

\subsection{Materials and Analysis}

The alloy AA5182 (Al-4.63\%Mg-0.49\%Mn-0.17\%Fe-0.04\% Cu) was chosen for testing because of its long freezing range and susceptibility to hot tearing. To examine the effect of as-cast porosity on the semi-solid behavior, tests were performed on both as-cast material and as-cast plus hot isostatic pressing (HIP) material. The HIP process consists of a high temperature, high pressure cycle designed to remove as-cast porosity. For this work, the proprietary DENSAL ${ }^{2}$ II HIP process was used.

Cylindrical tensile specimens of as-cast material were machined from a Direct Chill (DC) cast ingot, with their long axis oriented normal to the casting direction and parallel to the broad face. They were extracted from material approximately $\sim 6-10 \mathrm{~cm}$ below the surface of the ingot. The HIP condition specimens were machined from two blocks of as-cast material that had undergone the HIP cycle. These blocks were cut from same cast ingot as the as-cast specimens such that the as-cast and HIP specimen orientation and positioning relative to the surface of the ingot were similar. The test specimen geometry, shown in Fig. 1, contains a central gauge region with a reduced cross-sectional area $15 \mathrm{~mm}$ in length and $5 \mathrm{~mm}$ in diameter

A series of tensile deformation experiments were conducted between 500 and $580^{\circ} \mathrm{C}$, at a strain rate of $\sim 0.001 \mathrm{~s}^{-1}$, on the as-cast and the HIP materials to measure the semi-solid constitutive behavior. The experimental summary is provided in Table A. In the context of this work the flow stress is defined as the peak stress value over the range of strain $0<\varepsilon<$ 0.01. In many of the experiments softening was observed and hence a steady-state flow stress was not achieved as normally defined. The strain-to-failure is calculated based on the

\footnotetext{
${ }^{1}$ Dynamic Systems Inc., Poestenkill, NY, USA

${ }^{2}$ Bodycote Inc, London, $\mathrm{OH}$
} 
diametral reduction in the gauge as measured by a laser dilatometer immediately prior to specimen fracture.

To characterize the porosity and homogenization of the initial undeformed material, x-ray micro-tomography (XMT) and scanning electron microscope - energy dispersive spectroscopy (SEM-EDS) techniques were applied. XMT images of the internal damage caused by the semi-solid deformation process were also acquired for as-cast specimens tested at 500 and $550^{\circ} \mathrm{C}$, and a HIP specimen tested at $560^{\circ} \mathrm{C}$. Quantitative results were obtained through image analysis of the tomographic datasets using the software packages ImageJ [38] and Amira $^{3}$, while the composition data from SEM-EDS was subjected to a rank sort analysis using a technique previously developed by Ganesan et al. [39].

\subsection{A New Semi-Solid Deformation Methodology}

The focus of the new methodology is to improve both thermal and deformation control, and the measurement of strain. The fixed-grip challenge has been addressed through use of a Gleeble module known as a 'low-force jaw set'. This module, which is designed for application of small loads, allows for free expansion of one end of the specimen during heatup.

The Gleeble 3500 uses DC electric current to heat tensile specimens via resistive heating, and a servo-hydraulic system for deformation. Thermal control of the Gleeble requires a continuous feedback loop between the specimen temperature and software controlling the electric current input. Loss of control feedback will cause termination of the experiment. This loss of feedback arises when the control thermocouple detaches from the specimen, and occurs frequently during semi-solid testing due to localized surface melting. With regards to the deformation behavior, the challenge arises from the movement of the free end of the specimen during heat-up due to thermal expansion.

One feature of the Gleeble apparatus is that during specimen heat-up, an asymmetric parabolic temperature profile develops along the specimen length. The parabolic shape results from the combination of electrical-resistive heating along the specimen length, and localized heat loss at the ends of the specimen via the water-chilled copper grips. Furthermore, the shape can vary from test to test. To address this issue, the specimen gauge region was intentionally made relatively small. This region of reduced cross-section will have the highest current density and thus will be hottest.

\footnotetext{
${ }^{3}$ Mercury Computer Systems, Chelmsford, MA, USA
} 
By taking advantage of the parabolic temperature distribution and the near isothermal conditions within the reduced area region, it has been possible to develop a solution to the problem of control thermocouple detachment (failure). The idea is to provide thermal control via two thermocouples. One thermocouple (TC\#1, in the centre of the gauge region, Fig. 1) is used during heat-up to a set temperature near the solidus, while a second thermocouple (TC\#2, just outside the gauge region, Fig. 1) is used during final heating to the test temperature and also during deformation. Due to the parabolic temperature distribution and the difference in cross-sectional area, TC\#2 remains at a significantly lower temperature during testing as compared to TC\#1, and thus does not experience localized surface melting. Fig. 2 outlines the methodology used to conduct the experiments, which was written as a program in the Gleeble Scripting Language. In the first stage, the specimen is quickly heated until the reading at $\mathrm{TC} \# 1$ is $400^{\circ} \mathrm{C}$. In the second stage, the temperature of the specimen is controlled by TC\#2 and is increased at a slow rate. Since the temperature needed at TC\#2 to achieve the test temperature in the reduced area region near TC\#1 is not known a priori, the difference in temperature between the two thermocouples, $\Delta T$, is continually recorded during the second stage of the control program. A linear correlation for $\Delta T$ as a function of the temperature at TC\#2 is developed and is continually refined until TC\#1 stops functioning. The specimen temperature continues to be increased, until $T_{\mathrm{TCH} 2}+\Delta T$ is equal to the test temperature.

Also shown in Fig. 2 is the new methodology for improving deformation control and measurement. Deformation control is improved by firstly moving the cross-head precisely to offset the thermal expansion. After a $30 \mathrm{~s}$ hold at the test temperature for thermal stability, the cross-head is displaced at a rate of $50 \mu \mathrm{m} \mathrm{s}^{-1}$, in increments of $25 \mu \mathrm{m}$. After each increment in displacement, the force is measured. If the load cell records a force of $15 \mathrm{~N}$ or greater, it is assumed that the cross-head is aligned with the end of the specimen. At this point, the crosshead is displaced for a set distance in a set time in order to create the desired deformation conditions within the semi-solid specimen. During deformation, the evolution in force and diametral change are recorded. The force is measured using a $1000 \mathrm{lb}$ load cell. The diametral change is measured remotely using a Beta LaserMike ${ }^{4} 162-100$ laser dilatometer, since the force that acts to close the jaws on a contact dilatometer could be greater than the compressive strength of the material. The laser dilatometer is positioned near the centre of the gauge region but slightly offset from TC \#1.

\footnotetext{
${ }^{4}$ Beta LaserMike, Dayton, OH, USA
} 
This new Two Thermocouple Technique (2TC) provides an improved methodology for measurement of semi-solid constitutive behavior. However, three important limitations should be noted. Firstly, the linear correlation for $\Delta T$ is related to strain since the ratio of crosssectional area at TC\#2 to TC\#1 will increase as the specimen is deformed in tension. As a result, the gauge region could be hotter than calculated based on the correlation. For example, for a set-point temperature of $550^{\circ} \mathrm{C}$, a strain of 0.15 will lead to a temperature increase due to deformation of $6^{\circ} \mathrm{C}$. However, strains of this magnitude were rarely achieved in the current experiments. Secondly, although the laser is positioned near the centre of the gauge region, it may not be aligned precisely with the small region of strain localization. The strain-to-failure may therefore be greater than the strains reported here. Thirdly, due to the misalignment of the laser dilatometer as compared to strain localization, and also the accumulation of internal damage during deformation [40], it is still not possible to determine the true stress - true strain curve of the semi-solid material.

The typical evolution of temperature, diametral change in the gauge region, and force with time obtained from the 2TC technique is shown in Figs. 3 and 4. The results shown are for a test temperature of $550^{\circ} \mathrm{C}$ and a total strain of 0.02 . In most of the experiments, TC\#1 failed completely before the start of deformation. However, in this particular case, the weld at TC\#1 did not fail and thus the thermocouple continued functioning during the entire deformation process. Furthermore, this specimen was instrumented with a third thermocouple, TC \#3, on the shoulder opposite to TC\#2.

Referring firstly to the evolution of temperature with time, it can be seen from Fig. 3 that the specimen heats up to the test temperature in a controlled manner. The changes in heating rate at 75 and $120 \mathrm{~s}$ are part of the normal control heat-up algorithm. The large thermal spike in all three thermocouples at $~ 100 \mathrm{~s}$ was abnormal and was interpreted by the control algorithm as a failure of TC\#1, and thus $\Delta T$ was fixed at $72^{\circ} \mathrm{C}$ and no longer updated. The sample was then heated to the calculated set-point temperature based on TC\#2 alone and held there for $30 \mathrm{~s}$. At the start of deformation (marker ' $A$ ' in Fig. 3), the actual temperature at TC\#1, which was still functioning, was $550^{\circ} \mathrm{C}$. At the end of deformation $(55 \mathrm{~s}$ later and $\varepsilon$ $=0.028$ ), the temperature in the reduced area region had changed by $1^{\circ}$, to $549^{\circ} \mathrm{C}$. This value, while indicating a trend, is within the measurement error of the Gleeble apparatus. Since the desired temperature at the location of TC\#1 was $550^{\circ} \mathrm{C}$, it is clear that control based on a setpoint temperature at TC\#2 can successfully be used to control the temperature with the gauge length to a reasonable degree of accuracy. 
Referring next to the evolution of diametral change and force, three different regions can be seen in Fig. 4. In the first part of the curve, the specimen diameter increases at a constant rate, corresponding to the thermal expansion. In the second part of the curve, the specimen diameter continues to increase but at an irregular rate, due to localized melting within the gauge length. In both these regions, the measured force is close to zero, and the observed oscillations are caused either by experimental noise or friction related to apparatus-specimen interaction during thermal expansion. In the third part of the curve, beginning at marker ' $A$ ' (Fig. 4), the specimen yields and deforms in tension. The diameter decreases and the load cell measures the force required for this deformation to occur.

\section{Results and Analysis}

Firstly, the as-cast and HIP microstructure in the initial undeformed state is characterized. Secondly, the semi-solid deformation process is characterized via (a) analysis of fracture surfaces obtained using an SEM, (b) analysis of the semi-solid tensile constitutive behavior, and (c) analysis of tomographic images of tensile specimens deformed when semi-solid.

\subsection{Initial Conditions of the As-Cast and HIP Materials}

The as-cast porosity and solute micro-segregation were characterized in the initial undeformed state of both the as-cast and HIP materials to determine the effect of HIP processing on the microstructure and the melting behavior. Fig. 5 shows $2 \mathrm{D}$ cross-sectional slices from 3D tomographs of (a) undeformed as-cast material and (b) undeformed HIP material at a resolution of $\sim 2.5 \mu \mathrm{m}$ per voxel side. The black areas of Fig. 5 denote voids, while the light or white areas denote regions / phases enriched in higher atomic number solutes (e.g. Mn, Fe). These solute-enriched regions are most likely intermetallics located between grains or triple points.

It is clear from Fig. 5(a) that industrially DC cast aluminum alloys contain significant microporosity. This porosity, which forms due to a combination of changing gas solubility, shrinkage and thermomechanical loading during the casting process, appears well distributed with morphologies ranging from circular to elongated and tortuous. Image analysis of the 3D tomographs was used to quantify the initial state of porosity in as-cast AA5182. The material contains an initial porosity $(\% P)$ of $0.3-0.5 \%$, a void number density $\left(n_{\mathrm{v}}\right)$ of $433 \mathrm{~mm}^{-3}$, and an average void radius $\left(r_{\text {avg }}\right.$ ) of $7.5 \mu \mathrm{m}$. Due to a resolution limit of $2.5 \mu \mathrm{m}$ per voxel side, the small voids with radius less than $3.1 \mu \mathrm{m}$ were not included in the analysis. Thus, there is clearly much microporosity distributed throughout the as-cast material, and some of the voids 
can be quite large, on the order of 50-74 $\mu \mathrm{m}$. Maire et al. [41] have also quantified the distribution of voids in as-cast AA5182, but using synchrotron XMT. In their work, the following values were measured: $\% P \sim 0.1 \%, n_{\mathrm{v}} \sim 2025 \mathrm{~mm}^{-3}$, and $r_{\mathrm{avg}} \sim 4 \mu \mathrm{m}$. The results from the two studies are comparable apart from the void number density. This difference can be explained by comparing the resolution in the two studies. In Maire et al.'s study, the tomography resolution, at $0.7 \mu \mathrm{m}$ per voxel, was higher than the $2.5 \mu \mathrm{m}$ size used in the current work. Consequently, the myriad of small voids occurring around second phase particles, observed by Maire et al., were too small to be included in the void number density calculation performed in the current analysis.

In contrast, the HIP material, Fig. 5(b), does not appear to contain any porosity. It would thus appear that the HIP processing method has 'closed' the original as-cast porosity, an effect which has been previously documented (e.g. [42]). Although there may still be voids remaining in the HIP material, these voids are below the $2.5 \mu \mathrm{m}$ voxel size of the tomographic scan. Fig. 5 also illustrates that the HIP process has resulted in the homogenization of the higher atomic number solutes since the light regions are both reduced in volume fraction and appear more rounded. However, these images cannot be used to examine the effect of the HIP process on the segregation of the major solute element, $\mathrm{Mg}$, since its $\mathrm{x}$-ray attenuation is similar to Al. To determine the degree of segregation of $\mathrm{Mg}$ in both the as-cast and HIP materials, an SEM-EDS compositional analysis technique known as Weighted Interval Rank Sort (WIRS) was performed [39]. The results of this analysis, for 100 different compositional data points, are shown in Fig. 6. This figure provides an estimate of $\mathrm{Mg}$ segregation during solidification by assuming that the location with the lowest $\mathrm{Mg}$ content is the dendritic core and thus $f_{\mathrm{s}}=0$, and that the location with the highest $\mathrm{Mg}$ content is the last liquid to solidify in the interdendritic region and thus $f_{\mathrm{s}}=1$. As can be seen in the Fig. 6, the composition of $\mathrm{Mg}$ in the as-cast material varies between $\sim 3.0$ at $\%$ at the dendrite core to 8.9 at $\%$ in the interdendritic liquid, while the compositional variation in the HIP material was between 4.9 at $\%$ and 5.7 at\%. Thus, it is clear from Fig. 6 that the HIP processing method has significantly chemically homogenized the structure. The implications of this in terms of interpretation of the mechanical properties including ductility are discussed in Section 4.

\subsection{Characterization of Semi-Solid Deformation}

\section{(A) Fracture Surface Observations}

SEM images of fracture surfaces taken from as-cast AA5182 specimens tested via the 2TC methodology are shown in Fig. 7. Four images are shown, corresponding to test temperatures 
between 500 and $560^{\circ} \mathrm{C}$. In Fig. $7(\mathrm{a}), 500^{\circ} \mathrm{C}$, the fracture surface contains complex topography, indicative of ductile fracture. In Fig. $7(\mathrm{~b}), 520^{\circ} \mathrm{C}$, the fracture surface is similar to that at $500^{\circ} \mathrm{C}$, although it appears that some of the isolated regions of material appear smooth and glassy-like. In Fig. 7 (c), $540^{\circ} \mathrm{C}$, much of the fracture surface is covered in small nodules, indicative of small amounts of liquid between the dendrites. In Fig. $7(\mathrm{~d}), 560^{\circ} \mathrm{C}$, the fracture surface is dominated by a smooth and glassy-like appearance, indicative of a significant amount of liquid.

\section{(B) Semi-solid Constitutive Behavior}

The results of the tensile deformation experiments conducted on both the as-cast and HIP AA5182 materials are shown in Figs. 8 and 9. In Fig. 8, the stress-strain behavior of four ascast specimens, tested at $520,527,535$, and $545^{\circ} \mathrm{C}$, is provided. These stress-strain curves have been calculated from both the diametral change in the gauge region with time and force change with time measured during deformation. These results show a general decrease in the flow stress with increasing temperature and a decrease in the strain-to-failure with increasing temperature. Fig. 8 also shows that an increase in the rate of softening (i.e. a decrease in stress with increasing strain) is occurring with increasing temperature. This softening is due to the accumulation of internal damage during deformation, as previously discussed in [40] and [43]. However, since stress is determined from a cross-sectional area estimate based on the external specimen diameter, its true value is underestimated because of the internal damage. Between 527 and $545^{\circ} \mathrm{C}$ the fraction solid is estimated to change by $\sim 1.5 \%$ [44], while the flow stress decreased by $17.5 \%$. Thus, semi-solid flow stress appears to be highly sensitive to fraction solid.

The flow stress data together with the strain-to-failure data for both the as-cast material and HIP material is presented in Fig. 9. Starting firstly with the stress response, both materials show typical behavior - i.e. a gradual decrease in flow stress with increasing temperature up to the so-called point of mechanical coherency, where the flow stress rapidly drops. The measured flow stresses for the two materials are quite similar in the range 500 to $\sim 530^{\circ} \mathrm{C}$. In this temperature range, the alloy is (almost) fully solid so both materials should have the same strength. In the as-cast material, the strength continues to slowly decrease with increasing temperature and fraction liquid until $560^{\circ} \mathrm{C}$, where the mechanical coherency point is reached and the material loses virtually all its strength. In the HIP material, the mechanical coherency point occurs at a higher temperature, $570^{\circ} \mathrm{C}$. In terms of the ductility, it is clear from the data presented in Fig. 9 that in both materials the drop in ductility occurs at higher fraction as compared to the mechanical coherency. Based on the data shown, the temperature of zero- 
ductility was measured to be $548^{\circ} \mathrm{C}$ in the as-cast material and $565^{\circ} \mathrm{C}$ in the HIP material. It is also obvious that the HIP material exhibits a generally higher strain-to-failure than the as-cast material and that difference in ductility into the two materials exceeds the difference in flow stress.

A series of experiments were also carried out to assess the repeatability of the semi-solid strength measurements of the $2 \mathrm{TC}$ technique. A total of eleven tests were carried out at 550 and $560^{\circ} \mathrm{C}$ on the HIP material. The measured values of flow stress were found to be quite consistent, at $13.3 \pm 0.40 \mathrm{MPa}$ for $550^{\circ} \mathrm{C}$ and $12.4 \pm 0.35 \mathrm{MPa}$ for $560^{\circ} \mathrm{C}$. Thus, the $2 \mathrm{TC}$ technique provides both accurate and repeatable data.

(C) X-ray Micro-Tomography

To examine the impact of as-cast porosity and the liquid phase on deformation, XMT was used to compare the extent of internal deformation in the as-cast and HIP specimens. Fig. 10 shows 2D cross-sectional slices from the 3D tomographic images of (a) as-cast material deformed at $550^{\circ} \mathrm{C}(\varepsilon=0.001)$, (b) HIP material deformed at $560^{\circ} \mathrm{C}(\varepsilon=0.09)$, and (c) as-cast material deformed at $500^{\circ} \mathrm{C}(\varepsilon=0.08)$ at a resolution of $\sim 12 \mu \mathrm{m}$ per voxel side. The images shown were taken from a region of material 1 to $2 \mathrm{~mm}$ away from the fracture surface.

The effect of as-cast porosity on semi-solid tensile deformation can be seen clearly in the 2D cross-sectional slices of deformed material, shown in Fig. 10. In comparing these images, it appears that the as-cast semi-solid specimen, Fig. 10(a), contains voids which are larger and much more numerous as compared to the HIP semi-solid specimen, Fig. 10(b). In fact, only one large crack was observed in this HIP specimen, and it was located near the weld point for the control thermocouple. This weld point is believed to have acted as a stress riser during semisolid deformation, causing the crack to form.

The effect of the liquid phase on semi-solid tensile deformation can be seen by comparing the two images 10(a) and 10(c). Three salient observations can be made. Firstly, the amount of internal damage in the fully-solid specimen, Fig. 10(c), appears to be much less as compared to the semi-solid specimen, Fig. 10(a). Secondly, the voids in Fig. 10(c) appear much more rounded as compared to Fig. 10(a). Thirdly, some of the voids in Fig. 10(a) appear to have formed along common lines, possibly the grain boundaries that would have contained liquid during deformation, whereas in Fig. 10(c), the voids remained isolated. Thus, it would appear that the role of the liquid is to aid void nucleation, growth and coalescence. 


\section{Discussion}

\subsection{Evolution of Fraction Solid with Temperature}

One of the difficulties with the semi-solid deformation methodology is the difficulty associated with quantification of fraction solid. In general, the evolution of fraction solid with temperature is experimentally determined via cooling from the liquid to solid phase. In the current approach, the experiments were conducted via heating and partial remelting of the solid specimen. Since the fraction solid/temperature relationship is going to be different depending on whether the sample is undergoing cooling or heating, the actual faction solid obtained from a partial remelting experiment is difficult to ascertain. Furthermore, in the range of interest relevant to hot tearing, $0.9<f_{\mathrm{s}}<0.98$, the latent heat associated with the phase change can be small relative to the heat capacity of the solid material. Thus, this portion of the fraction solid/temperature relationship is difficult to measure and interpret.

As preliminary work for this study, a number of different techniques including two-pan and single-pan [45] differential scanning calorimetry were used to measure the evolution of fraction solid with temperature of both as-cast and HIP AA5182 during melting processes. Although the chemical homogenization due to the HIP process will certainly affect the fraction solid/temperature relationship, none of the measurement results were consistent in their prediction of the evolution of fraction solid with temperature over the range $0.9<f_{\mathrm{s}}<$ 0.98 .

Due to the difficulties associated with measuring fraction solid, the fracture surface images shown in Fig. 7 were used to qualitatively validate the presence of the liquid phase during semi-solid tensile testing of AA5182. These images clearly show that the solidus temperature is between 520 and $540^{\circ} \mathrm{C}$, and that by $560^{\circ} \mathrm{C}$, much of the grains boundaries are covered in liquid. These observations are similar to the fraction solid/temperature relationship published by Thompson et al. [44], who determined that the solidus temperature for as-cast AA5182 was $525^{\circ} \mathrm{C}$. These observations are also similar with the $\mathrm{Mg}$ solute profile of as-cast AA5182, shown in Fig. 6, since the equilibrium solidus temperature of the interdendritic liquid is $\sim 518^{\circ} \mathrm{C}$. In the chemically homogenized HIP material, the equilibrium solidus temperature of the interdendritic liquid is $\sim 550^{\circ} \mathrm{C}$.

\subsection{Semi-Solid Constitutive Behavior}

The experimental data presented in Fig. 9 clearly shows the variation in constitutive behavior and ductility of as-cast and HIP AA5182 in the transition region between fully solid 
and semi-solid and delineates the mechanical coherency point in the two materials. Similar trends have previously been reported for AA5182 [25, 32], although their magnitude was found to be different (possibly due to compositional variation).

The combination of the SEM images shown in Fig. 7, and the stress-strain curves presented in Fig. 8, allow some insight to be gained into the mechanisms of semi-solid deformation. The fracture surfaces of the specimens deformed at 500 and $520^{\circ} \mathrm{C}$, Fig. 7(a) and (b), contain little evidence of liquid. At these temperatures, the material exhibits considerable ductility. The specimen tested at $527^{\circ} \mathrm{C}$, Fig. 8, also exhibits considerable ductility. While the test at $527^{\circ} \mathrm{C}$ was performed above the solidus temperature, it contained only a small amount of liquid. The microstructure in the specimen is believed to have consisted of of small isolated liquid pockets, small regions of liquid film and thus significant bridging between the grains. As the temperature is further increased, the measurements show decreased ductility, while fracture surfaces provide increasing evidence of the presence of liquid at the time of failure. At $545^{\circ} \mathrm{C}$, Fig. 8, failure occurred at low ductility, indicating that the liquid phase existed as a continuous film with limited solid bridging between the grains. At $560^{\circ} \mathrm{C}$, Fig. $7(\mathrm{~d})$, the fracture surface appears to have been largely covered by liquid during deformation, leading to a complete loss in ductility.

In comparison, the effect of liquid on semi-solid flow stress is more subtle in nature as the results shown in Fig. 9 indicate a gradual loss of flow stress as the temperature is increased towards the mechanical coherency point. In this case, the behavior observed is consistent with the liquid acting to reduce the effective load-bearing area of the tensile specimen, resulting in an apparent decrease in the flow stress. Material failure occurs when the strain at the local scale exceeds the (limited) semi-solid ductility.

The increase in ductility in the fully solid state is in good agreement with previously reported results [42]. The increase in mechanical coherency occurs because of the chemical homogenization undergone by the material during HIP processing, as shown in Figs. 5 and 6. It has previously been found by a number of researchers that mechanical coherency occurs at a fraction solid of $\sim 0.95[25,32]$. The results from the as-cast material experiments corroborate those earlier findings since the coherency temperature in the as-cast material, $560^{\circ} \mathrm{C}$, corresponds to a fraction solid of $\sim 0.95$ using the fraction solid/temperature relationship measured by Thompson [44]. Due to the chemical homogenization, the low melting temperature phases are not present. Thus the HIP specimens must be heated to a higher temperature to reach a fraction solid of 0.95 and exceed the mechanical coherency 
limit. In this case, the HIP process appears to have shifted the temperature at which the material is at a fraction solid of 0.95 by $\sim 10^{\circ} \mathrm{C}$, to $570^{\circ} \mathrm{C}$.

In terms of ductility, as shown in Fig. 9, the effect of the HIP treatment on ductility is significantly greater than its effect on flow stress, both above and below the solidus. There are two possible mechanisms that would account for this behavior. Firstly, as shown in Fig. 5, the HIP process is removing the as-cast porosity. Assuming that the grains are completely surrounded by liquid films, the pre-existing voids found in the as-cast material will act as stress risers enabling increase accumulation of damage and failure along the grain boundaries. Even with significant solid bridging between grains, the presence of voids will still provide stress concentration, and will promote the loss of ductility at small values of strain. Secondly, the homogenization may have altered the amount and distribution of liquid films at the grain boundaries for a given fraction solid, and thus has retarded the process of strain localization and material failure.

\subsection{Hot Tearing and Porosity}

The observed effect of as-cast porosity on tensile deformation, shown in Figs. 8-10, indicate that its presence significantly reduces semi-solid ductility. While the ductility behavior reported in Table A provides a macroscopic overview of the as-cast and HIP material behavior, analysis at the micro-scale level provides further insight into the relationship between porosity and hot tearing. A quantitative comparison of the voids found in the three specimens shown in Fig. 10 was performed to provide a description of the evolution in internal damage caused by deformation both with and without porosity. This quantification, shown in Table B, characterizes the effect of fraction solid and material condition on the fraction porosity $(\% P)$, maximum void radius $\left(r_{\max }\right)$, and the void to strain ratio $(V S R)$ in the

three deformed specimens from Fig. 10. The VSR is defined as $1-\varepsilon_{d} / \varepsilon_{t}$, where $\varepsilon_{\mathrm{d}}$ is the diametral strain assuming a fully dense specimen and $\varepsilon_{\mathrm{t}}$ is the strain including both diameter reduction and growth of internal voids, and provides a measure of the percentage of strain being accumulated internally. A description of the quantitative analysis methodology has been reported previously [46].

The results shown in Table B indicate that the void related measurements are largest in the semi-solid as-cast material, specimen ' $A$ ', as compared to the other two specimens. For example, the fraction porosity in $A$ was $\sim 2.5 \%$ although the measured diametral strain was quite small. This increase in porosity, from $\sim 0.3 \%$ in the as-cast undeformed material, 
Fig. 5(a), to $2.5 \%$ in the as-cast semi-solid deformed material, Fig. 10(a), demonstrates the effectiveness of liquid in enabling void growth and internal damage. Although specimens $B$ and $C$ were subjected to much more tensile deformation than $A$, this deformation was not accompanied by a significant increase in fraction porosity. Thus, it is clear from both Table B and Fig. 10 that it is not just the presence of liquid or as-cast porosity but the combination of the two that enables extensive internal damage to form in semi-solid materials leading to a hot tear. As shown qualitatively in Figs. 10(b) and (c), and quantitatively in Table B, if neither liquid nor voids are present then there is limited distribution of internal damage. Away from the fracture surface, for example at the locations of Figs. 10(b) and (c), internal deformationbased damage does not occur.

The effect of as-cast porosity on hot tearing is clearly related to the relative locations of the voids, the liquid, and grain boundaries. At high fraction solid, the majority of the remaining molten material is eutectic liquid located as films along grain boundaries and as isolated pockets within the interdendritic regions. These same regions will also contain most of the ascast porosity [8, 47]. On application of load, it may be postulated that both the isolated liquid pockets and the pores will act as small cracks and concentrate stress, while the continuous films will concentrate strain. As proposed by Phillion et al., [43] the presence of free surface in the liquid in the form of as-cast porosity acts as a stress riser and allows strain to be accommodated by growth of this pre-existing void through the liquid along the grain boundary. When this free surface is missing, as is the case in the HIP material, voids must nucleate within the liquid via vacancy coalescence [48], or via imperfections on the solidliquid interface to allow for development of internal damage. It can be hypothesized that when liquid is not present, as in the specimen shown in Fig. 10(c), void nucleation does not occur until the intermetallic particles separate from the matrix phase, or fracture [49], and void growth is limited because there is no liquid to concentrate strain, and allow for grain boundary tearing.

In semi-solid material with pre-existing porosity, stresses will concentrate between the voids, and coalesce to form a hot tear. Without pre-existing porosity, more strain must be applied to increase the dislocation / vacancy concentration and coalescence, and thus to create voids in a two-phase material composed of liquid and a highly compliant solid. It follows that material with fewer tendencies to form shrinkage-based porosity (e.g. short freezing range alloys) and material with a finer grain size (i.e. smaller and more evenly distributed pockets of residual liquid at high fractions solid) is predicted to be less prone to hot tearing. These predictions match prior research including the work of Spittle and Cushway [50], who showed 
experimentally that both grain refinement and compositional variation reduced hot tearing susceptibility in $\mathrm{Al}-\mathrm{Cu}$ alloys in the range $1-7 \% \mathrm{Cu}$.

The impact of this interplay between porosity and hot tearing is important and critical for a number of materials applications. For example, it can be applied to predict hot tearing susceptibility in the case of DC casting in aluminum alloys. In the case of DC cast cylindrical billets, hot tearing occurs in the central part of the casting, when high casting rates are used. High casting rates lengthen the mushy zone, increase the solidification time, and therefore create a coarse grain structure, insufficient feeding to compensate the solidification shrinkage and the likelihood of increased porosity. The introduction of porosity acts as nucleation sites for hot tearing. In the case of DC cast rectangular ingots, hot tearing occurs under conditions which can be described as a 'hot casting' (i.e. reduced bottom block filling time and reduced cooling water flow rate). While the casting surface is not normally prone to porosity, the hot casting conditions increase the surface solidification time and thus increase porosity. The presence of porosity would exacerbate strain localization, and greatly increase hot tearing susceptibility. Therefore, in both cases, greater control over the as-cast porosity would lead to a reduction in hot tearing by reducing nucleation sites and thus increasing the amount of deformation required for hot tear propagation.

\section{Conclusions}

A new experimental methodology has been developed to measure the tensile constitutive behavior of semi-solid aluminum alloys. Specimens machined from the aluminum alloy AA5182 in the as-cast and as-cast plus hot isostatic pressing states were tested at temperatures between $500^{\circ} \mathrm{C}$ and $580^{\circ} \mathrm{C}$ at a strain rate of $\sim 0.001$. X-ray micro-tomography was performed to quantify the initial porosity distribution in the materials tested, and the effects of porosity and liquid on the development of internal damage during deformation, and by extension, hot tearing. The following conclusions can be drawn:

1. The two thermocouple technique provides reasonable thermal control during semi-solid tensile deformation. This technique eliminates earlier issues associated with the thermocouple weld detachment and thermal expansion.

2. The two thermocouple technique also improves cross-head displacement control, allowing for application of specific amounts of strain while eliminating the uncertainty associated with lengthwise thermal expansion. 
3. The semi-solid ductility was improved by the HIP process by as much as a factor of 7 . This ductility increase is due to the removal of the as-cast porosity and homogenization of the microstructure.

4. The HIP process increased the mechanical coherency temperature by $\sim 10^{\circ}$ to $570^{\circ} \mathrm{C}$. It is thought that this increase is due primarily to a shift in the relationship between fraction solid and temperature caused by chemical homogenization.

5. The application of the HIP process to the as-cast material has greatly reduced the amount of internal damage accumulated during semi-solid deformation, indicating that pre-existing as-cast porosity plays an important role in the formation of hot tears. Reducing or eliminating this porosity would make aluminum alloys more resistant to hot tearing.

\section{Acknowledgements}

The authors would like to acknowledge NSERC, EPSRC (GR/T26344), and Alcan Intl. for financial support, and thank D. Fuloria for assistance with XMT, D. Liu for assistance with the Gleeble, and R. Atwood for characterizing the micro-segregation in both materials.

\section{References}

[1] J. Campbell and T. W. Clyne, Cast Metals 3 (224) 224-6.

[2] T. W. Clyne and G. J. Davies, Br. Foundryman 74 (1981) 65-73.

[3] D. Davidson, D. Viano, L. Liming and D. St.John, Shape Casting: J. Campbell Symp., San Francisco, CA TMS, 2005, p. 175.

[4] J. M. Drezet and M. Rappaz, Light Metals 2001, New Orleans, LO TMS, 2001, p. 887-93.

[5] I. Farup, M. Rappaz and J. M. Drezet, Acta Met. 49 (2001) 1261-9.

[6] D. G. Eskin, Suyitno and L. Katgerman, Progress in Materi. Sci. 49 (2004) 629-711.

[7] J. Campbell, Castings. Butterworth Heinemann, 2 ed., 1991.

[8] P. D. Lee and J. D. Hunt, Acta Mat. 45 (1997) 4155-69.

[9] P. D. Lee, R. C. Atwood, R. J. Dashwood and H. Nagaumi, Mater. Sci. Eng. A 328 (2002) 213-22.

[10] T. S. Piwonka and M. C. Flemings, Trans. AIME 236 (1966) 1157-65.

[11] J. D. Zhu, S. L. Cockcroft and D. M. Maijer, Metall. Mater. Trans. A 37A (2006) 107585.

[12] P. D. Lee, A. Chirazi and D. See, J. Light Metals 1 (2000) 15-30.

[13] J. P. Hirth, G. M. Pound and G. R. St. Pierre, Metall. Trans. A 1 (1970) 939-45.

[14] Suyitno, W. H. Kool and L. Katgerman, Metall. Mater. Trans. A 35A (2004) 2917-26.

[15] J. Sengupta, S. L. Cockcroft, D. M. Maijer and A. Larouche, Mater. Sci. Eng. A 397 (2005) 157-77.

[16] B. Commet, P. Delaire, J. Rabenberg and J. Storm, Light Metals 2003, San Diego, CA TMS, 2003, p. 711-7.

[17] H. Fredriksson and B. Lehtinen, Int. Conf. Solidification \& Casting, Met. Soc. London 2 (1977).

[18] Suyitno, W. H. Kool and L. Katgerman, Mater. Sci. Forum 396-402 (2002) 179-84. 
[19] A. K. Dahle, S. Instone and T. Sumitomo, Metall. Mater. Trans. A 34A (2003) 105-13A.

[20] M. C. Flemings, Metall. Trans. A 22A (1991) 957-81.

[21] M. Ferrante and E. De Freitas, Mater. Sci. Eng. A 271 (1999) 172-80.

[22] J. M. Drezet, O. Ludwig, M. M'Hamdi, H. G. Fjasr and C. L. Martin, Light Metals 2004, Charlotte, NC TMS, 2004, p. 655-60.

[23] D. H. St. John and A. K. Dahle, Acta Met. 47 (1999) 31-41.

[24] A. K. Dahle and L. Arnberg, Acta Met. 45 (1997) 547-59.

[25] L. J. Colley, M. A. Wells and D. M. Maijer, Mater. Sci. Eng. A 386 (2004) 140-8.

[26] D. Fabregue, A. Deschamps, M. Suery and W. J. Poole, Metall. Mater. Trans. A 37A (2006) 1459-67.

[27] S. Instone, D. H. St.John and J. Grandfield, Int. J. Cast Met. Res. 12 (2000) 441-56.

[28] J. Kron and H. Fredriksson, Int. Symp. Liq. Met. \& Casting, Nancy, Fr SF2M-Paris, 2003, p. 393-400.

[29] J. A. Spittle, S. G. R. Brown, J. D. James and R. W. Evans, Phys. Sim. Casting, Hot Rolling \& Weld., Tsukuba, JP Nat. Res. Inst. Met., 1997, p. 81-91.

[30] M. R. Twite, J. A. Spittle and S. G. R. Brown, Int. J. Forming Process. 2004, p. 233-60.

[31] W. M. van Haaften, W. H. Kool and L. Katgerman, Mater. Sci. Eng. A 336 (2002) 1-6.

[32] P. Ackermann, W. Kurz and W. Heinemann, Mat. Sci. Eng. 75 (1985) 79-86.

[33] B. Magnin, L. Maenner, L. Katgerman and S. Engler, Mater. Sci. Forum 217-222 (1996) 1209-14.

[34] J. Langlais and J. E. Gruzleski, Mater. Sci. Forum 331-337 (2000) 167-72.

[35] D. Larouche, J. Langlais, W. Wu and M. Bouchard, Metall. Mater. Trans. B 37B (2006) 431-43.

[36] A. R. E. Singer and S. A. Cottrel, J. Inst. Metals 73 (1947) 33-54.

[37] T. Nakagawa, P. Suvanchai, T. Okane and T. Umeda, Mater. Sci. Forum 215-216 (1996) 377-84.

[38] M. D. Abramoff, P. F. Magelhaes and R. S.J., Biophotonics Intl. 11(7) (2004) 36.

[39] M. Ganesan, D. Dye and P. D. Lee, Metall. Mater. Trans. A 36A (2005) 2191-204A.

[40] A. B. Phillion, S. L. Cockcroft and P. D. Lee, Scripta Mat. 55 (2006) 489-92.

[41] E. Maire, J. C. Grenier, D. Daniel, A. Baldacci, H. Klocker and A. Bigot, Scripta Mat. 55 (2006) 123-6.

[42] J. T. Staley, M. Tiryakioglu and J. Campbell, Mater. Sci. Eng. A 460-461 (2007) 324-34.

[43] A. B. Phillion, PhD, University of British Columbia (2007).

[44] S. Thompson, S. L. Cockcroft and M. A. Wells, Mater. Sci. Techn. 20 (2004) 497-504.

[45] H. B. Dong, M. R. M. Shin, E. C. Kurum, H. Cama and J. D. Hunt, Fluid Phase Equilib. 212 (2003) 199-208.

[46] A. B. Phillion, P. D. Lee and S. L. Cockcroft, Frontiers in Solidification Science, Warrendale, PA TMS, 2007, p. 569.

[47] H. Nagaumi, K. Komatsu, M. Uematsu, N. Hasisawa and Y. Nishikawa, J Japan Inst Light Metals 6 (1999) 13-9.

[48] H. Fredriksson, M. Haddad-Sabzevar, K. Hansson and J. Kron, Mater. Sci. Techn. 21 (2005) 521-9.

[49] G. Huber, Y. Brechet and T. Pardoen, Acta Mat. 53 (2005) 2739-49.

[50] J. A. Spittle and A. A. Cushway, Met. Techn. 10 (1983) 6-13. 


\section{Tables}

Table A: Experimental conditions and results (The flow stress is given in MPa).

\begin{tabular}{|c|c|c|c|c|c|}
\hline \multicolumn{3}{|c|}{ As Cast Material } & \multicolumn{3}{|c|}{ HIP Material } \\
\hline $\begin{array}{l}\text { Temp. } \\
\left({ }^{\circ} \mathrm{C}\right)\end{array}$ & $\begin{array}{l}\text { Flow } \\
\text { Stress }\end{array}$ & $\begin{array}{c}\text { Diametral } \\
\text { Strain-to- } \\
\text { Failure }\end{array}$ & $\begin{array}{c}\text { Temp. } \\
\left({ }^{\circ} \mathbf{C}\right)\end{array}$ & $\begin{array}{c}\text { Flow } \\
\text { Stress }\end{array}$ & $\begin{array}{c}\text { Diametral } \\
\text { Strain-to- } \\
\text { Failure }\end{array}$ \\
\hline 570 & 1.75 & 0 & 580 & 1.2 & 0 \\
\hline 560 & $7.2 ; 1.4 ; 1$ & $\begin{array}{c}0.0008 \\
0 ; 0\end{array}$ & 575 & 1.2 & 0 \\
\hline 557 & 6.4 & 0 & 572 & 1.2 & 0 \\
\hline 548 & 11.5 & 0 & 570 & $\begin{array}{c}2.71 ; 4.12 \\
9.5\end{array}$ & $0 ; 0 ; 0$ \\
\hline 545 & 12.4 & $0.01^{*}$ & 565 & $\begin{array}{c}9.3 ; 10.0 \\
11.7\end{array}$ & $\begin{array}{c}0 ; 0.01 \\
0.021^{*}\end{array}$ \\
\hline 540 & 13.1 & $0.01^{*}$ & 560 & $\begin{array}{l}12.5 ; 12.2 ; \\
12.3 ; 12.9 ; \\
\quad 12.0\end{array}$ & $\begin{array}{c}0.008 ; 0.022 \\
0.085 ; 0.09 \\
0.1^{*}\end{array}$ \\
\hline 535 & 14.5 & $0.015^{*}$ & 550 & $\begin{array}{l}13.0 ; 13.3 ; \\
13.5 ; 14.0 ; \\
13.1 ; 13.3\end{array}$ & $\begin{array}{c}0.008 ; 0.009 \\
0.028 ; 0.045 \\
0.124 ; 0.142^{*}\end{array}$ \\
\hline 527 & 14.8 & 0.035 & 535 & 15.6 & $0.011^{*}$ \\
\hline 520 & 16.2 & $0.057^{*}$ & 515 & 17.6 & $0.192^{*}$ \\
\hline 500 & 20.4 & $0.075^{*}$ & 500 & 21.4 & $0.184^{*}$ \\
\hline
\end{tabular}

*Denotes semi-solid ductility limit

Table B: Comparison of damage-related measurements via XMT in select as-cast and HIP specimens.

\begin{tabular}{ccccccc}
\hline Specimen & Material & $\boldsymbol{T}\left({ }^{\circ} \mathbf{C}\right)$ & $\boldsymbol{\varepsilon}$ & $\boldsymbol{\% P}$ & $\boldsymbol{R}_{\max }$ & $\boldsymbol{V S \boldsymbol { R }}$ \\
\hline$A$ & As-cast & 550 & 0.001 & $2.5 \%$ & 274 & 1 \\
$B$ & HIP & 560 & 0.09 & $0.47 \%$ & 223 & 0.022 \\
$C$ & As-cast & 500 & 0.08 & $0.31 \%$ & 140 & 0.03 \\
\hline
\end{tabular}

\section{Figure Headings}

Figure 1: Specimen geometry showing dimensions and locations of control thermocouples.

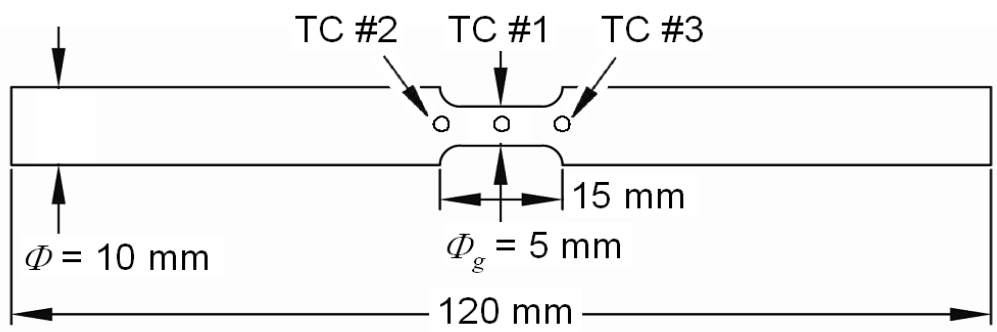


Figure 2: Flowchart outlining the Two Thermocouple Control Technique for conducting semi-solid deformation tests in the Gleeble 3500 thermomechanical simulator.

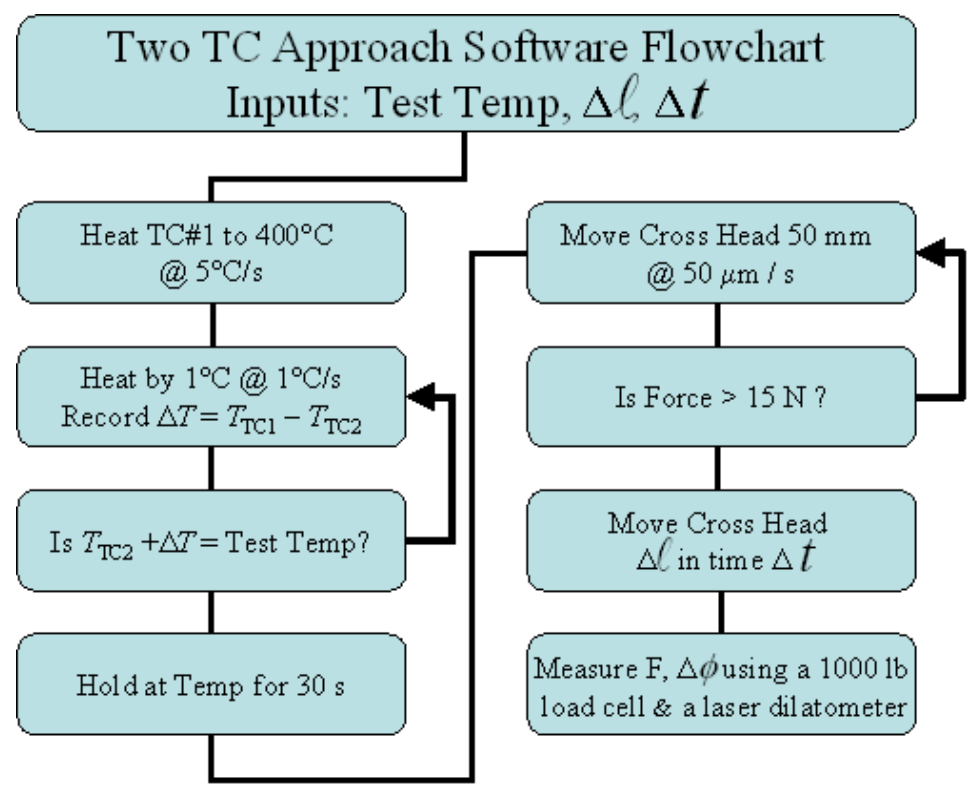

Figure 3: An example of the temperature-time profile obtained using the 2TC technique, $550^{\circ} \mathrm{C}$ test, HIP material. The arrow at ' $\mathrm{A}$ ' marks the start of deformation.

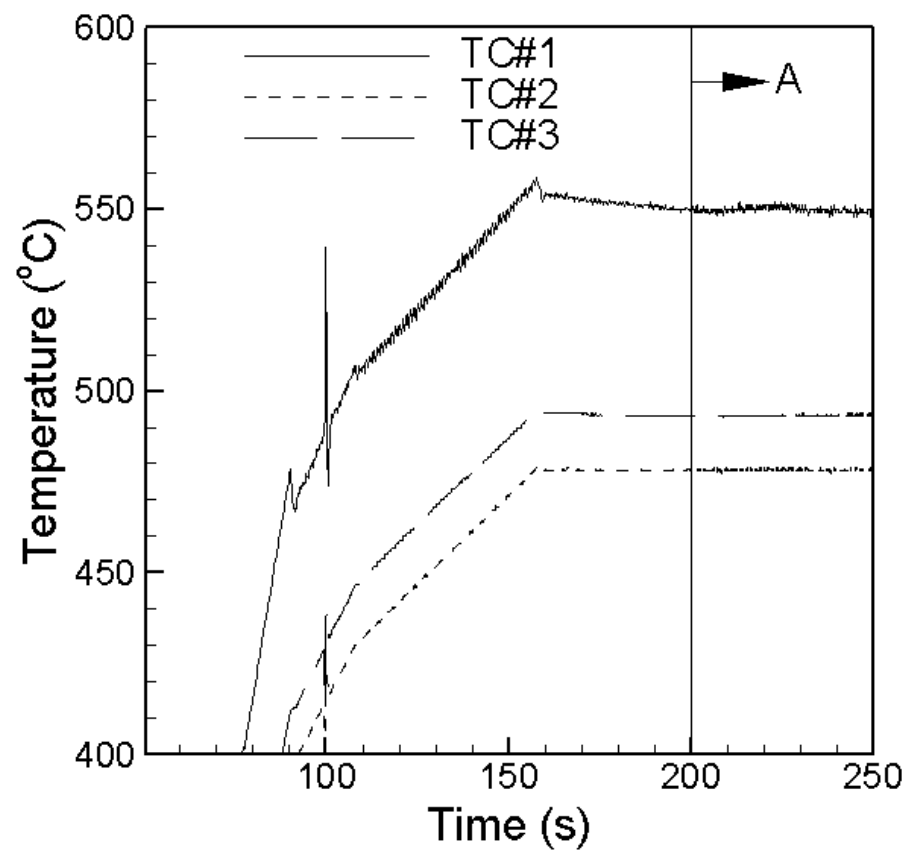


Figure 4: An example of the force and dimetral change during semi-solid deformation $550^{\circ} \mathrm{C}$ test, HIP material. The arrow at ' $\mathrm{A}$ ' marks the start of deformation.

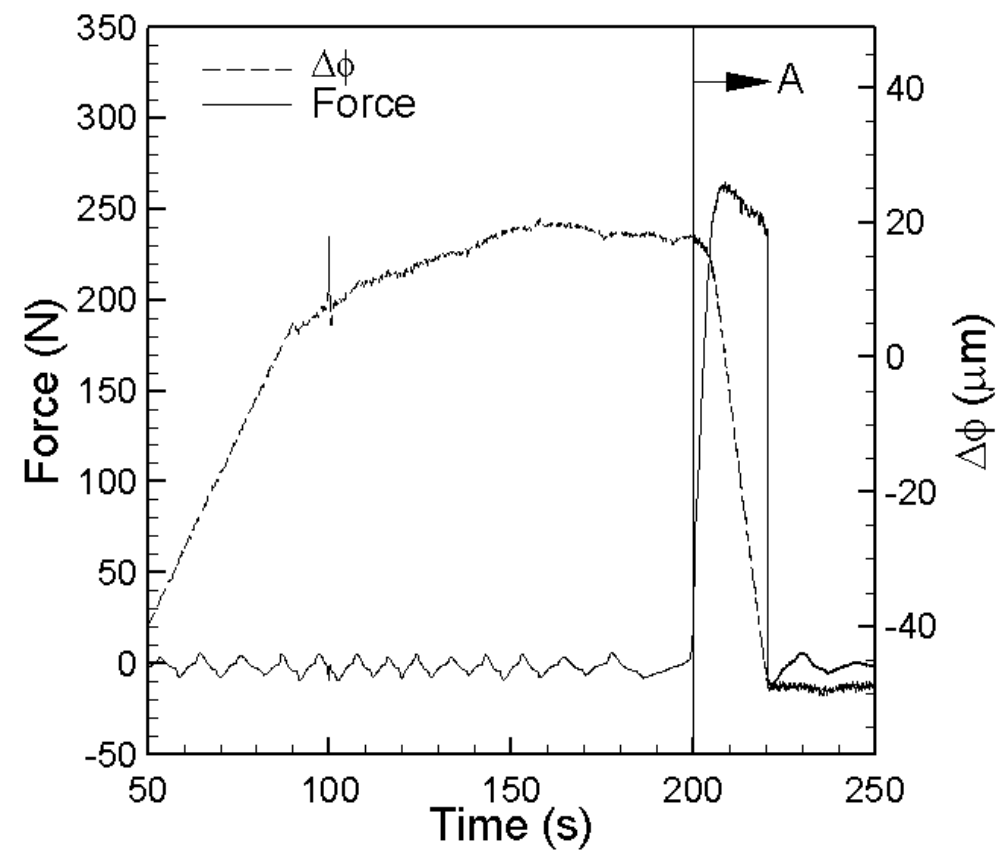

Figure 5: 2D cross-sectional slices from 3D tomography scans of the undeformed material: (a) as-cast AA5182, and (b) HIP AA5182.

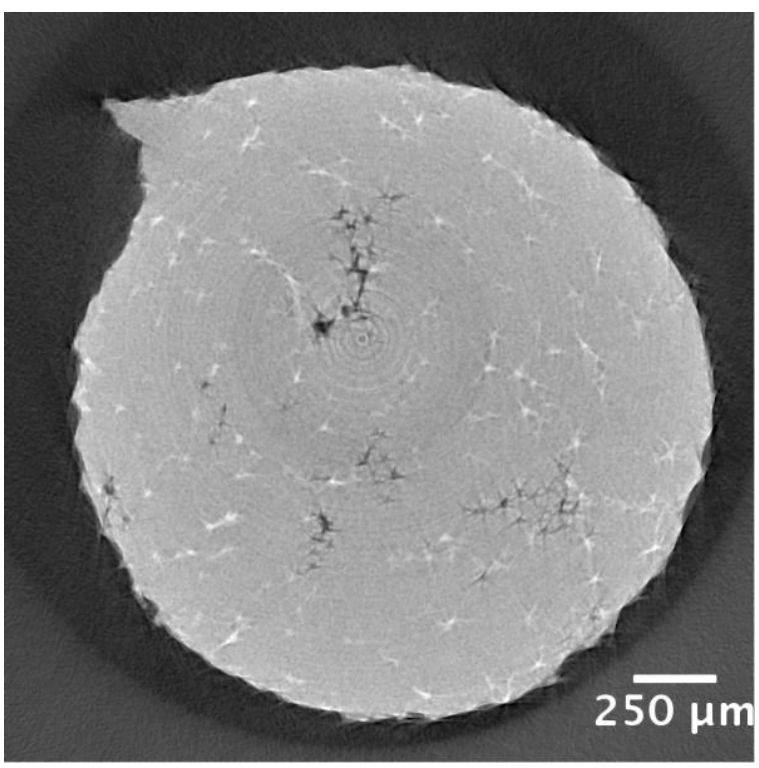

a)

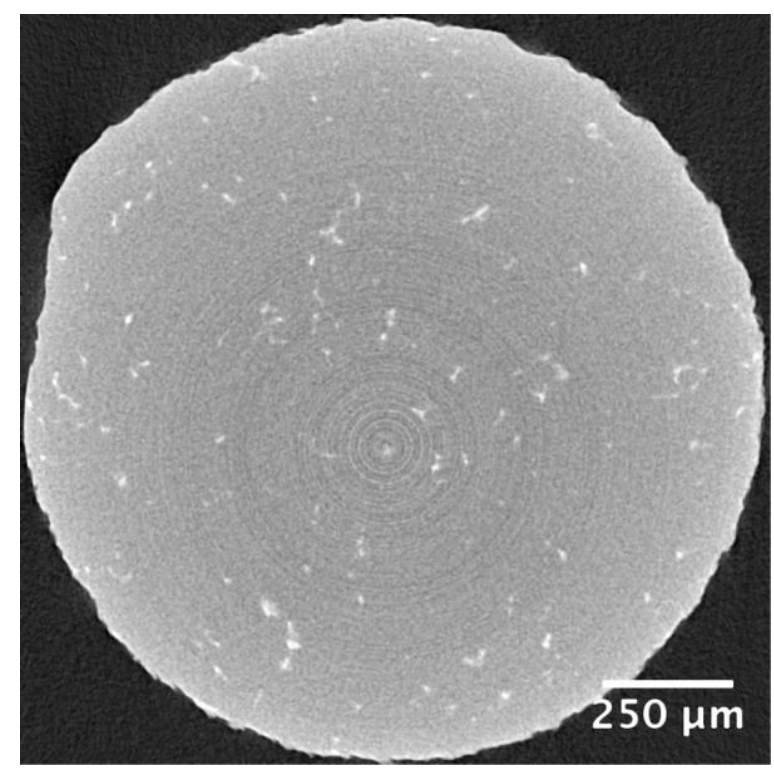

b) 
Figure 6: Solute profiles of Mg content in AA5182 in both the as-cast and HIP conditions.

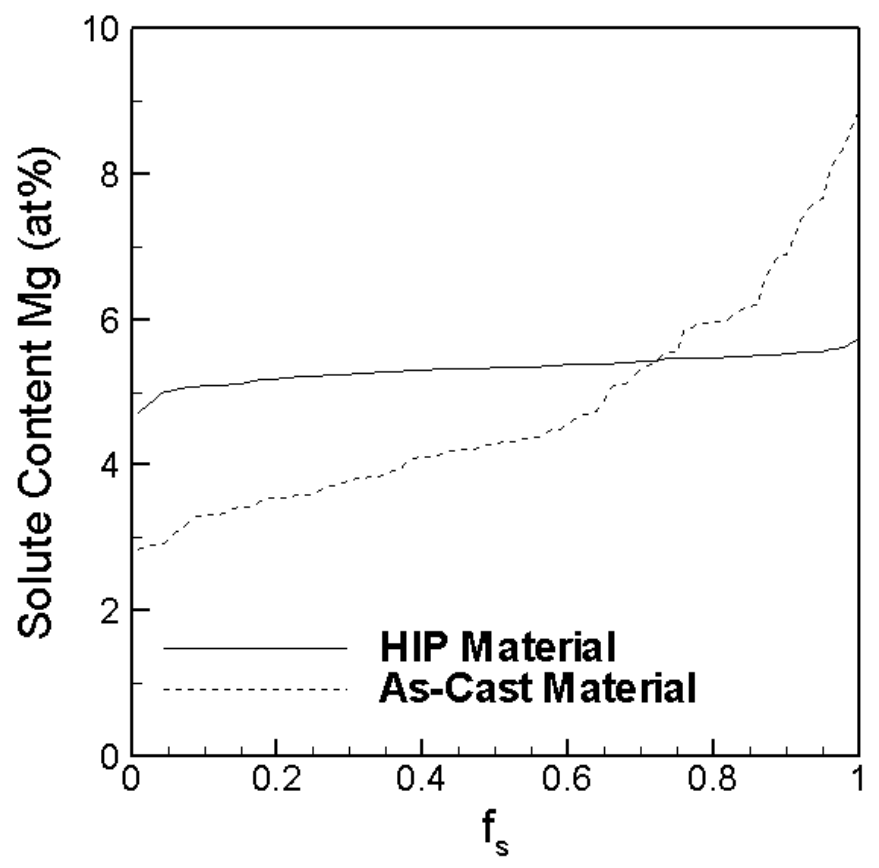

Figure 7: SEM Images of the fracture surface of as-cast AA5182 specimens tested using the $2 \mathrm{TC}$ methodology: (a) $500^{\circ} \mathrm{C}$, (b) $520^{\circ} \mathrm{C}$, (c) $540^{\circ} \mathrm{C}$, (d) $560^{\circ} \mathrm{C}$.

a)

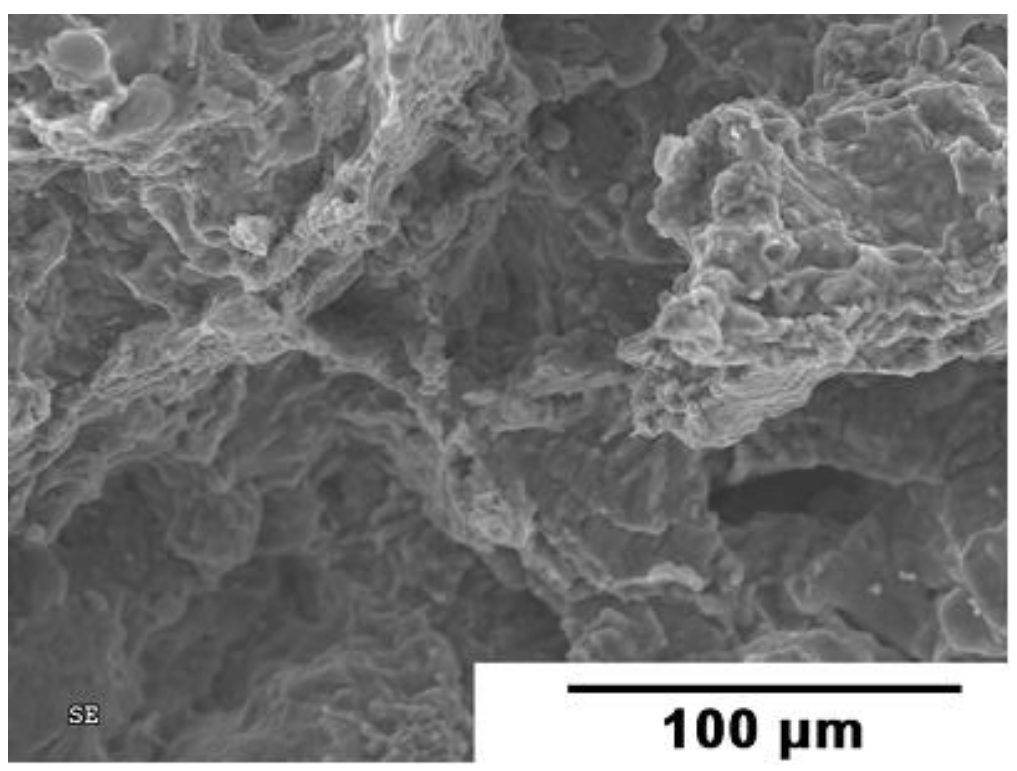


b)

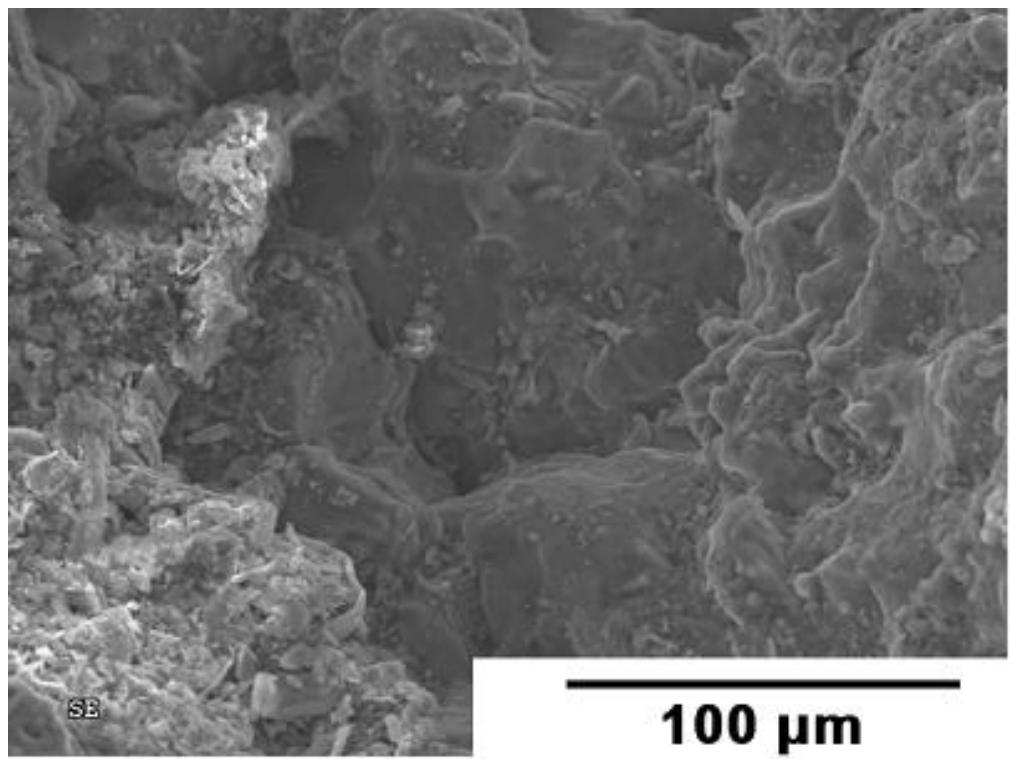

c)

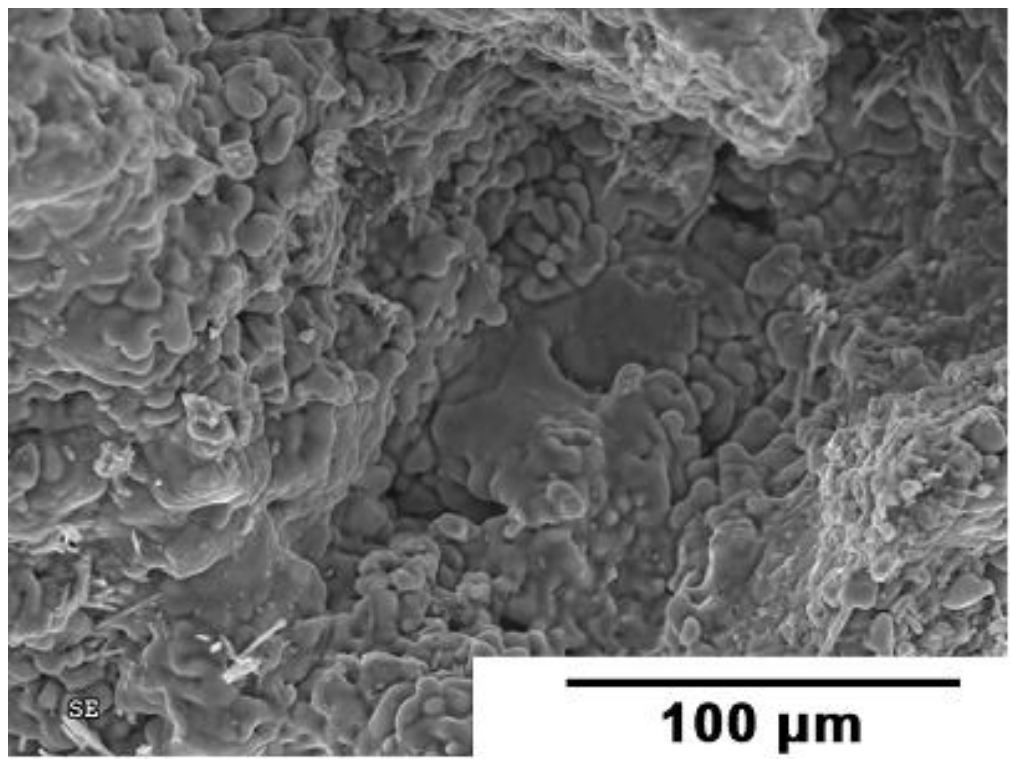

d)

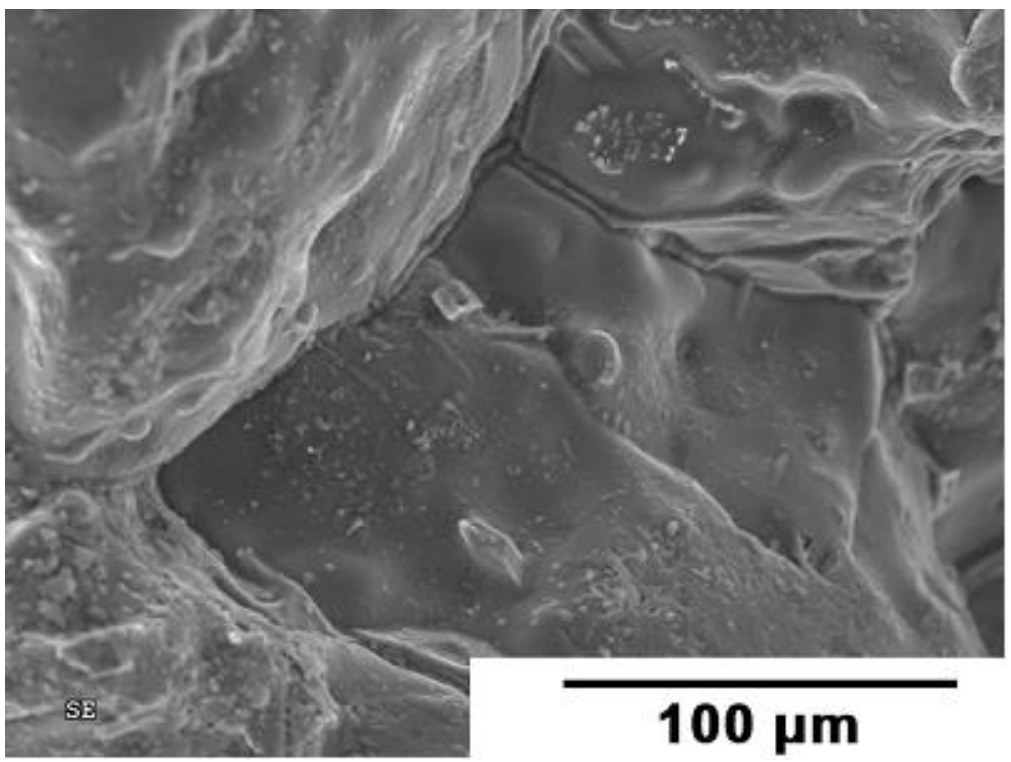


Figure 8: Stress-strain curve for as-cast AA5182 at 520, 527, 535 and $545^{\circ} \mathrm{C}$.

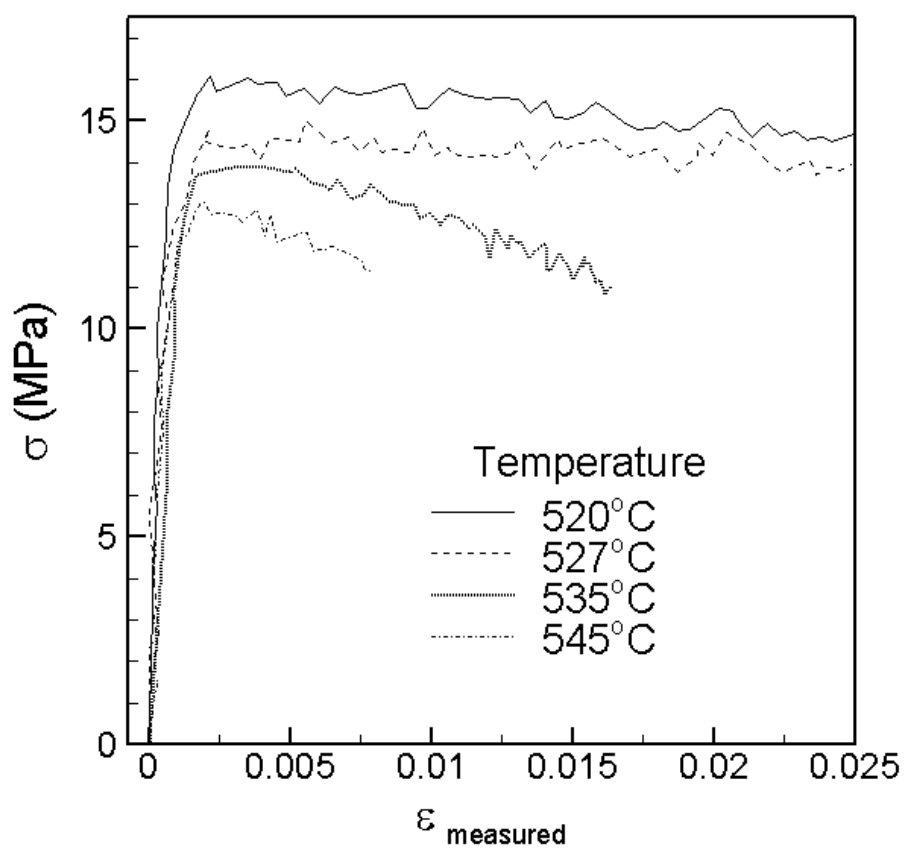

Figure 9: Variation in (a) flow stress and (b) strain-to-failure with temperature for ascast AA5182 and HIP AA5182.

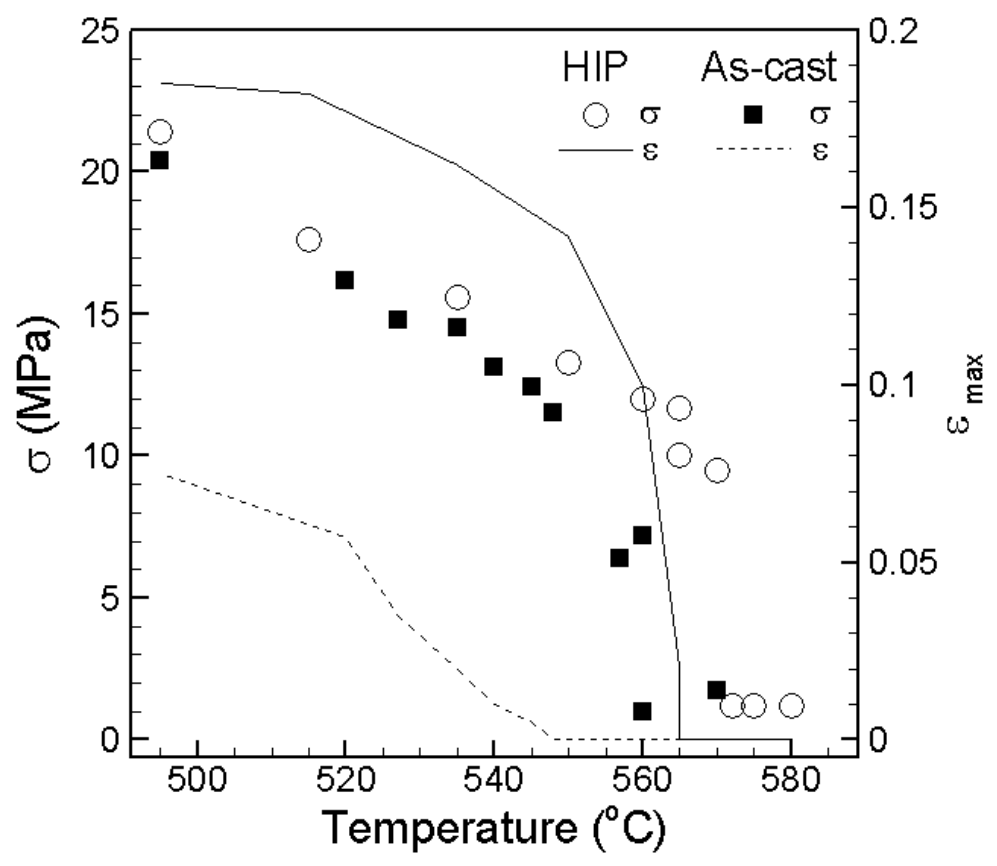


Figure 10: 2D cross-sectional slices from 3D tomography scans of deformed specimens: (a) as-cast AA5182 $\left(\mathrm{T}=550^{\circ} \mathrm{C}, \varepsilon=0.001\right)$, (b) HIP AA5182 $\left(\mathrm{T}=560^{\circ} \mathrm{C}, \varepsilon=0.09\right)$, and (c) as-cast $\mathrm{AA5182}\left(\mathrm{T}=500^{\circ} \mathrm{C}, \varepsilon=0.08\right)$.

a)

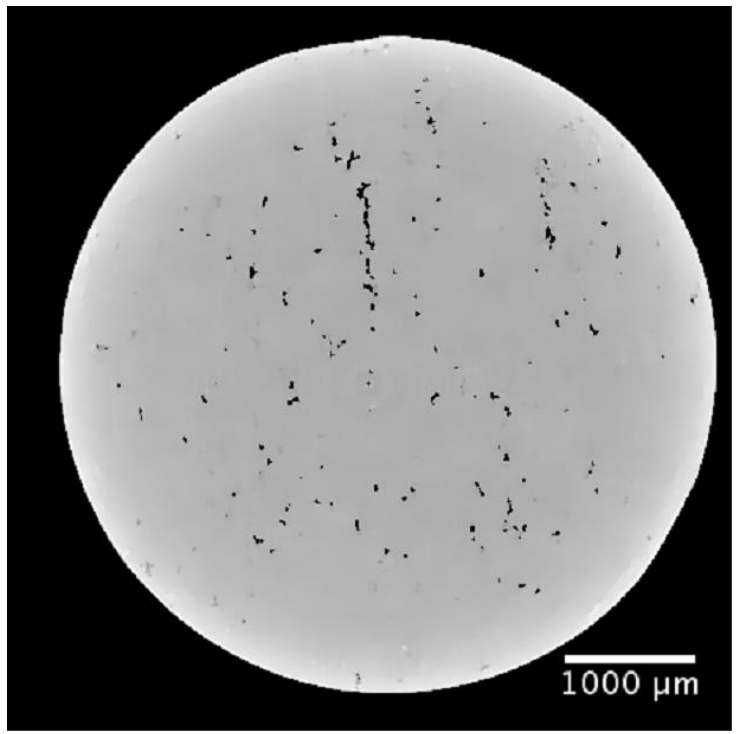

b)

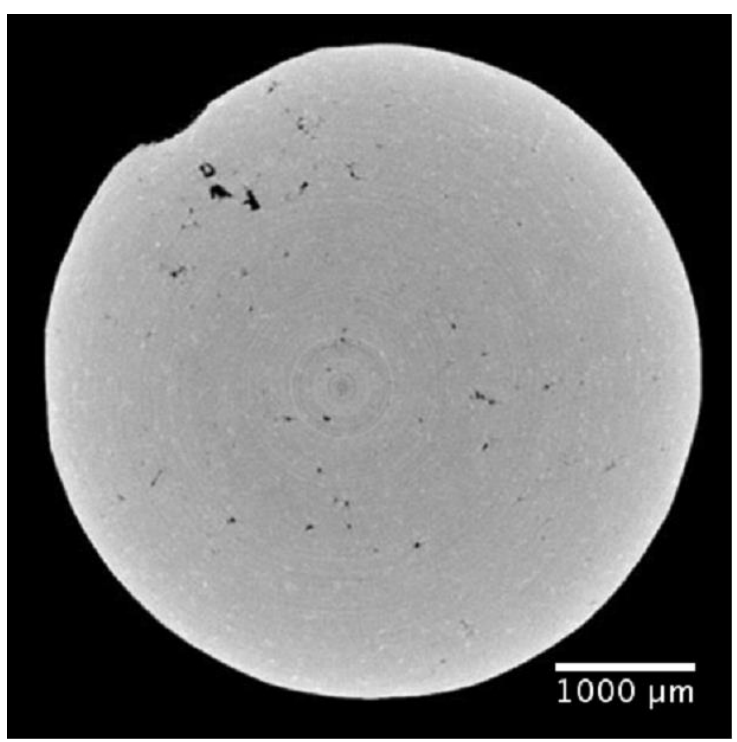

c)

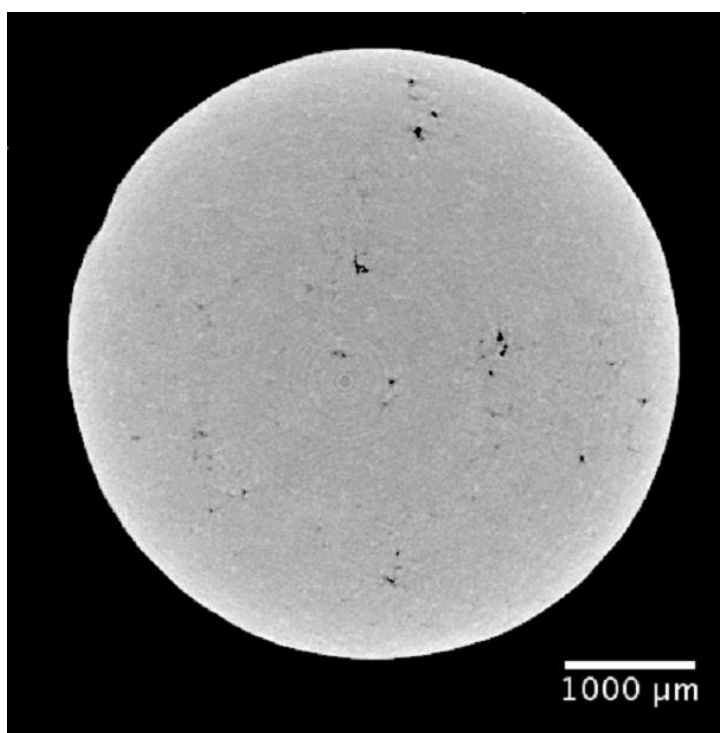

